\title{
RECURRENT INTESTINAL OBSTRUCTION IN THE NEONATAL PERIOD*
}

\author{
BY \\ K. DEVENS \\ From the Surgical Department of the Children's Hospital, University of Munich, Germany
}

Between 1956 and 1962, 238 newborn infants underwent laparotomy for intestinal obstruction at the Surgical Department of the Children's Hospital in Munich. This paper is concerned with 24 cases where a second operation was necessary because of persistence or recurrence of intestinal obstruction.

Table 1 shows the initial pathology and the findings when the abdomen was reopened. The commonest cause of recurrent obstruction was early and intensive adhesion (Table 2). There seem to be two reasons for this complication: first, injury to the intestinal serosa by extensive handling and by drying of the bowel while it lies outside the peritoneal cavity, and secondly a long period of aperistaltic ileus which increases the possibility of fibrous bands forming between the bowel loops. The early post-operative course is, therefore, important in this respect and we believe that peristalsis should be stimulated to return as soon as possible. Intraperitoneal cortisone may also be of value in preventing formation of adhesions; early results appear promising but are not yet conclusive. It seems to carry little danger to the anastomosis.

In several cases we found that the end-to-end anastomosis was either not patent or was not functioning properly. There were several reasons for this. When anastomosing two bowel ends that differ considerably in diameter it is necessary to cut the distal one very obliquely in order to obtain equal lumina. This may lead to considerable angulation of the intestine at the anastomosis, which predisposes to further kinking, and eventually complete obstruction can result. In some cases we think we were too economical with the resection of the blind or prestenotic intestinal loop. Nixon's (1960) work on this subject is, of course, well known and our experience confirms his view that one must, if possible, be generous in resecting the proximal non-functioning bowel. We feel that some of the hazards we had to deal with were due to a situation

\footnotetext{
* A paper read at a meeting of the British Association of Paediatric Surgeons in London, September 1962.
}

shown in Fig. 1. In three cases a leaking anastomosis was found and it was necessary to carry out further resection. In these the bowel had been left at the first operation with a doubtful blood supply.

Our patients with duodenal stenosis and atresia gave cause for particular concern in the post-operative period; in 12 of 52 cases the abdomen had to be reopened. In five of these, adhesions were the cause of the recurrent obstruction. In two instances there was partial necrosis of the jejunal loop; cases where the initial duodenal obstruction was treated by duodeno-jejunostomy. In one infant the duodenal stenosis persisted because congenital obstructing peritoneal bands had been incompletely divided. In four cases a large prestenotic duodenal sac led to kinking and obstruction at the anastomosis (Fig. 2). These cases also had a duodeno-jejunostomy.

The value of a transanastomotic tube, either through the mouth or through an enterostomy, is debatable. In some cases our impression was that it helped to promote an uneventful recovery; in others we felt that it had disadvantages. For example, when the anastomosis is narrow the tube may lead to its occlusion during the phase of temporary post-operative oedema. In one of our cases the distal end of the tube coiled up in the jejunum and caused an obstruction that necessitated a second operation.

The simultaneous occurrence of separate congenital malformations is well known. We operated on a case of double atresia of the jejunum and had to reoperate four days later because a colonic atresia had remained undetected. This anomaly is undoubtedly extremely rare, but the case shows that one must make absolutely certain that the whole intestinal tract is patent below an atresia.

Other factors than operative technique are, of course, concerned with normal post-operative bowel function. Careful pre-operative handling of the infant, the avoidance of extensive and unnecessary diagnostic procedures, accurate replacement of 
TABLE 1

238 OPERATIONS FOR INTESTINAL OBSTRUCTION IN THE NEWBORN, 1956-1962

24 CASES OF RECURRENT OR PERSISTENT OBSTRUCTION NECESSITATING SECOND OPERATION (Mortality: $71 \%$ )

\begin{tabular}{|c|c|c|c|}
\hline $\begin{array}{l}\text { Cause of } \\
\text { Original } \\
\text { Obstruction }\end{array}$ & $\begin{array}{c}\text { No. } \\
\text { of } \\
\text { Cases }\end{array}$ & $\begin{array}{l}\text { Cause of } \\
\text { Secondary } \\
\text { Obstruction }\end{array}$ & $\begin{array}{l}\text { No. } \\
\text { of } \\
\text { Cases }\end{array}$ \\
\hline $\begin{array}{l}\text { Duodenal atresia or sten- } \\
\text { osis: (associated with } \\
\text { malrotation of midgut } \\
\text { in } 4 \text { cases) }\end{array}$ & 12 & $\begin{array}{l}\text { Adhesions } \\
\text { Non-functioning of anas- } \\
\text { tomosis } \\
\text { Leakage at anastomosis } \\
\text { Inadequate division of } \\
\text { obstructing bands }\end{array}$ & $\begin{array}{l}5 \\
4 \\
2 \\
1\end{array}$ \\
\hline $\begin{array}{l}\text { Small bowel atresia } \\
\text { (multiple in } 2 \text { cases) }\end{array}$ & 4 & $\begin{array}{l}\text { Kinking at anastomosis } \\
\text { Leakage at anastomosis } \\
\text { Colonic atresia }\end{array}$ & $\begin{array}{l}2 \\
1 \\
1\end{array}$ \\
\hline Malrotation of midgut & 5 & $\begin{array}{l}\text { Adhesions } \\
\text { Kinking at anastomosis } \\
\text { Recurrence of volvulus }\end{array}$ & $\begin{array}{l}2 \\
2 \\
1\end{array}$ \\
\hline Meconium ileus & 2 & $\begin{array}{l}\text { Adhesions } \\
\text { Intussusception of small } \\
\text { bowel }\end{array}$ & $\begin{array}{l}1 \\
1\end{array}$ \\
\hline Diaphragmatic hernia & 1 & Small bowel adhesions & 1 \\
\hline
\end{tabular}

TABLE 2

REASONS FOR PERSISTENT OR RECURRENT OBSTRUCTION AFTER OPERATION FOR INTESTINAL OBSTR UCTION IN THE NEONATAL PERIOD

1. Peritoneal adhesions

2. Complications at the anastomosis:

(a) Failure to function

(b) Kinking

(c) Leakage

3. Lesions not detected at the original operation: colonic atresia

4. Persistence of the original pathology: congenital peritoneal bands

5 Recurrence of the original pathology:

6. Intussusception

fluid and electrolyte loss and prompt operation are all important. In the post-operative period, evidence of persistent or recurrent obstruction is common, but the causes are by no means always mechanical. In the early stages it may be due to plastic nonfibrotic adhesions or to paralytic ileus and should be treated conservatively. The most careful and accurate parenteral fluid therapy cannot replace oral feeding and gastro-intestinal tract absorption. Once this is achieved the child's general condition and intestinal function will improve rapidly, and we

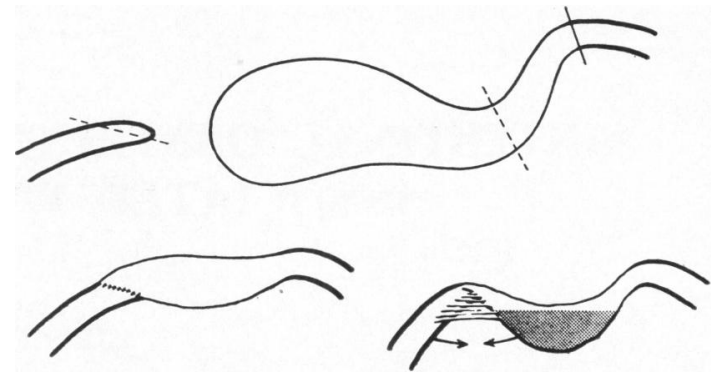

Fig. 1.-Intestinal atresia. Top: resection of prestenotic bowel was performed at the level of dotted line. Below: obstruction of anastomosis as a result of insufficient resection of the proximal loop.
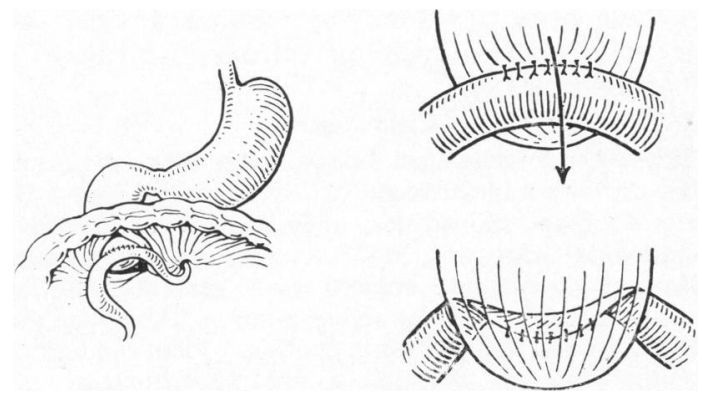

FIG. 2.-Duodenal atresia. Left: duodenojejunostomy was performed. Right: obstruction of anastomosis caused by a large prestenotic duodenal sac left in situ at the primary operation.

believe that one should aim at feeding, by tube if necessary, at the earliest possible moment. The fact that adhesions form early in the newborn baby indicates that the peritoneal response is rapid and that an intestinal anastomosis is well consolidated at an early stage. Peristalsis can, therefore, be stimulated by appropriate drugs. However, if there are signs of persistent or recurrent obstruction after operation, and conservative management does not lead to an early improvement, a mechanical obstruction will certainly be present and the abdomen should be reopened immediately. The high mortality rate $(71 \%$ in our cases), would probably have been lower if the second operation had been performed earlier.

\section{REFERENCE}

Nixon, H. H. (1960). Ann. roy. Coll. Surg. Engl., 27, 105. 